\title{
Potential impact of contrails on solar energy gain
}

\author{
P. Weihs ${ }^{1}$, M. Rennhofer ${ }^{3}$, D. J. Baumgartner ${ }^{2}$, J. Gadermaier ${ }^{1}$, J. E. Wagner ${ }^{4}$, J. E. Gehring ${ }^{1}$, and W. Laube ${ }^{1}$ \\ ${ }^{1}$ Institute of Meteorology, University of Natural Resources and Life Sciences, Peter Jordan Strasse 82, 1190 Vienna, Austria \\ ${ }^{2}$ Kanzelhöhe Observatory, University of Graz, 9521 Treffen, Austria \\ ${ }^{3}$ Austrian Institute of Technology, Giefinggasse 2, 1210 Vienna, Austria \\ ${ }^{4}$ Institute for Applied Remote Sensing, EURAC research, Viale Druso 1, 39100 Bolzano, Italy
}

Correspondence to: P. Weihs (weihs@mail.boku.ac.at)

Received: 21 March 2014 - Published in Atmos. Meas. Tech. Discuss.: 29 August 2014

Revised: 9 January 2015 - Accepted: 4 February 2015 - Published: 5 March 2015

\begin{abstract}
The effect of contrails on global short-wave radiation (sum of direct and downward diffuse solar radiation) and on solar energy gain was investigated. The study was performed during days with high contrail persistence and focused on situations where the contrails were obstructing the sun. Measurements of cloudiness using a fish-eye camera, diffuse and direct short-wave measurements and measurements of the short circuit current of three different types of photovoltaic (PV) modules were performed at the Kanzelhöhe Observatory ( $1540 \mathrm{~m}$ a.s.l.) with a time resolution of $1 \mathrm{~min}$ over a period of 1 year. The results show that contrails moving between sun and observer/sensor may reduce the global radiation by up to $72 \%$. An analysis of contrail persistence and the influence of contrails on global irradiance and solar energy gain is presented. The losses in solar energy gain that were recorded may be critical under specific circumstances.
\end{abstract}

\section{Introduction}

The effect of air traffic on climate has been a topic of research for at least 50 years. Most investigations have focused on the radiative forcing caused by contrails and by cirrus cloudiness originating from contrails. This has been examined by using radiative transfer models and by using, amongst others, satellite information on contrail optical thickness, contrail coverage, and man-made cirrus cloudiness. The mean annual radiative forcing estimate, e.g. for the specific location Herstmonceux (Stuber et al., 2006) is $0.75 \mathrm{~W} \mathrm{~m}^{-2}$ in the long wavelength range and $-0.5 \mathrm{~W} \mathrm{~m}^{-2}$ in the short wavelength range which amounts to a total radiative forcing of around $0.25 \mathrm{~W} \mathrm{~m}^{-2}$. Minnis et al. (2004) showed that $85 \%$ of the days with persistent contrails are also days with cirrus cloudiness.

Only few studies, however, have investigated the impact of contrails on ground-based irradiance by analysing groundbased measurements. Wendler et al. (2005) explored this effect within the scope of a case study using ground-based measurements of direct and diffuse irradiance and fish-eye photographs. They found a maximum decrease in global irradiance of up to $16 \%\left(116 \mathrm{~W} \mathrm{~m}^{-2}\right)$ when the contrails were moving between sun and observer. Between these obstruction events the diffuse irradiance was enhanced by up to $29 \%$ due to reflection and scattering of the direct radiation by the surrounding clouds. This increase in radiation does not only include the reflection and scattering by contrails but also the effect of cirrus cloudiness. Feister and Shields (2005) investigated the increase in diffuse irradiance solely caused by contrails and found enhancements of $8 \%$. Pfister et al. (2003) observed short-term enhancements in global irradiance of up to $60 \%$ which were caused by thin clouds but over the period of an hour the average increase would not be larger than $10 \%$. The studies mentioned above made use of groundbased global radiation measurements and were just based on a visual determination of the contrails using the fish-eye photographs. The automated all sky imaging systems usually had a field of view of $180^{\circ}$ and performed the measurements at intervals of at least $1 \mathrm{~min}$.

A preliminary study by Weihs et al. (2013), who analysed 8 months of data from Kanzelhöhe Observatory, Austria, determined a reduction in global irradiance by contrails obstructing the sun by up to $68 \%$. The number of days with persistent contrails were determined for each month. The winter 
months showed a higher number of days with around $30 \%$ of them with persistent contrails occurring in January 2011. In June 2011 only $10 \%$ of the days were observed with persistent contrails Overall, there are only few studies dealing with measurements of the effect of contrails on ground-based diffuse and direct irradiance. To the authors' knowledge, no studies have examined possible effects of contrails on solar energy production losses. The present study investigates the effect of contrails on short-wave global irradiance incident on a horizontal plane and on solar energy production. In a first step the preliminary study by Weihs et al. (2013) was continued by including more days and by performing the analysis for a time period of 1 year. Secondly, conclusions and estimations on a possible impact on solar energy gain have been made.

\section{Methods}

\subsection{Measurements}

The investigations were carried out at the Kanzelhöhe Observatory for Solar and Environmental Research, Carinthia, Austria $\left(46^{\circ} 40^{\prime} \mathrm{N}, 13^{\circ} 54^{\prime} \mathrm{E}\right)$ which is situated at $1540 \mathrm{~m}$ altitude. The Kanzelhöhe Observatory belongs to the University of Graz which performs various meteorological measurements. Typical climatic and synoptic measurements (air temperature and humidity, precipitation, wind speed and direction, air pressure, global radiation, sunshine duration) are also being performed by the Austrian weather service. The Kanzelhöhe Observatory also hosts an "AERONET" station (a sun-sky photometer instrument which routinely measures the aerosol optical depth at seven wavelengths, the single scattering albedo and the atmospheric column water vapour; Holben et al., 1998, 2001). A high quality radiation station (baseline surface radiation network (BSRN) standard) is just being installed. Routine measurements of global irradiance using EMS 11 silicon photodetector pyranometers have been performed at $1 \mathrm{~min}$ intervals since June 2010. At the same time, the short circuit current (current conversion efficiency at short circuit) of three different photovoltaic (PV) module types (crystalline silicon - c-Si: 220 Watt Peak (Wp) and $1.66 \mathrm{~m}^{2}$, amorphous silicon - a-Si: $95 \mathrm{Wp}$ and $1.45 \mathrm{~m}^{2}$ and cadmium telluride - CdTe: $75 \mathrm{Wp}$ and $0.72 \mathrm{~m}^{2}$ ) were recorded. The PV modules were mounted with a $35^{\circ}$ inclination, one of each type oriented towards south, one of each type oriented towards east and towards west (altogether nine PV modules). In addition, fish-eye photographs of the sky hemisphere with a $180^{\circ}$ field of view automatic camera (CMS Schreder) have been performed also using 1 min intervals.

\subsection{Visual detection of contrails}

From fish-eye photographs, videos were created for each week. Using these videos, days with contrail persistence and the time of day when sun obstructions by contrails occurred were visually identified. For most of the contrails, we could see the creation of contrails by aeroplanes. If the creation of contrails could not be observed, the identification of the contrails was made based on their typical linear shape. In case of doubt, when the clear identification between contrails and other wave shaped cirrus clouds (e.g. cirrus fibratus, radiatus or vertebratus) was not possible or when other clouds would obstruct the sun at the same time as the contrail, the case was omitted.

With the strong winds in these altitudes (above at least $8000 \mathrm{~m}$ a.s.l.), the contrails move fast. A contrail, created at a large distance from the observer (large zenith angle) may move out of sight of the observer within some minutes, but it may still remain visible for up to $60 \mathrm{~min}$ depending on the wind direction. A contrail is considered to be persistent when the contrail is still detectable after the originating plane has disappeared.

A sun obstruction occurred when the contrail moved between sun and observer (Figs. 1a-c, 2). This "obstruction" event was also clearly visible in the global radiation measurements which showed a reduction during this obstruction (Figs. 1c and 2). The main additional criteria for the selection of the "contrail events" were firstly the existence of a reduction in global radiation occurring simultaneously with the obstruction of the sun by the contrail visible on the fish-eye photographs. Secondly, the global radiation should reach the same intensity after the obstruction event as before the event (taking into account a slight change in position of the sun by performing radiative transfer calculations). It could also be observed that there was an increased global radiation ("enhancement"), as compared to global radiation during cloudless conditions, by reflection of cirrus clouds and contrails between the obstruction events. This enhancement in global radiation becomes larger with optically thicker clouds and with increasing cloud fractions as long as the sun is not obscured by clouds (Pfister et al., 2003). The present study discriminates between short time enhancement just before and after an obstruction event due to reflections and scattering of the direct solar radiation towards the pyranometer by the contrails (see Fig. 1c), and longer time enhancement due to clouds and contrails on the sky which are not very close to the position of the sun.

Since cloud fraction is a relevant additional information this quantity was determined for the selected days using the findcloud software (CMS Schreder): Fig. 1a shows a short time sequence of a day with a strong contrail persistence. During this time period the cloud fraction is around 0.4 . Altogether, for $90 \%$ of all the selected cases the cloud fraction was equal or below two tenths. Only $10 \%$ of the cases showed larger cloud fractions. During time periods with larger cloud fractions, surrounding clouds (including contrails) may however lead to maximum enhancements in global radiation of up to $10 \%$ (see Sect. 4), which means that the global radiation is higher than $10 \%$ compared to cloud- 

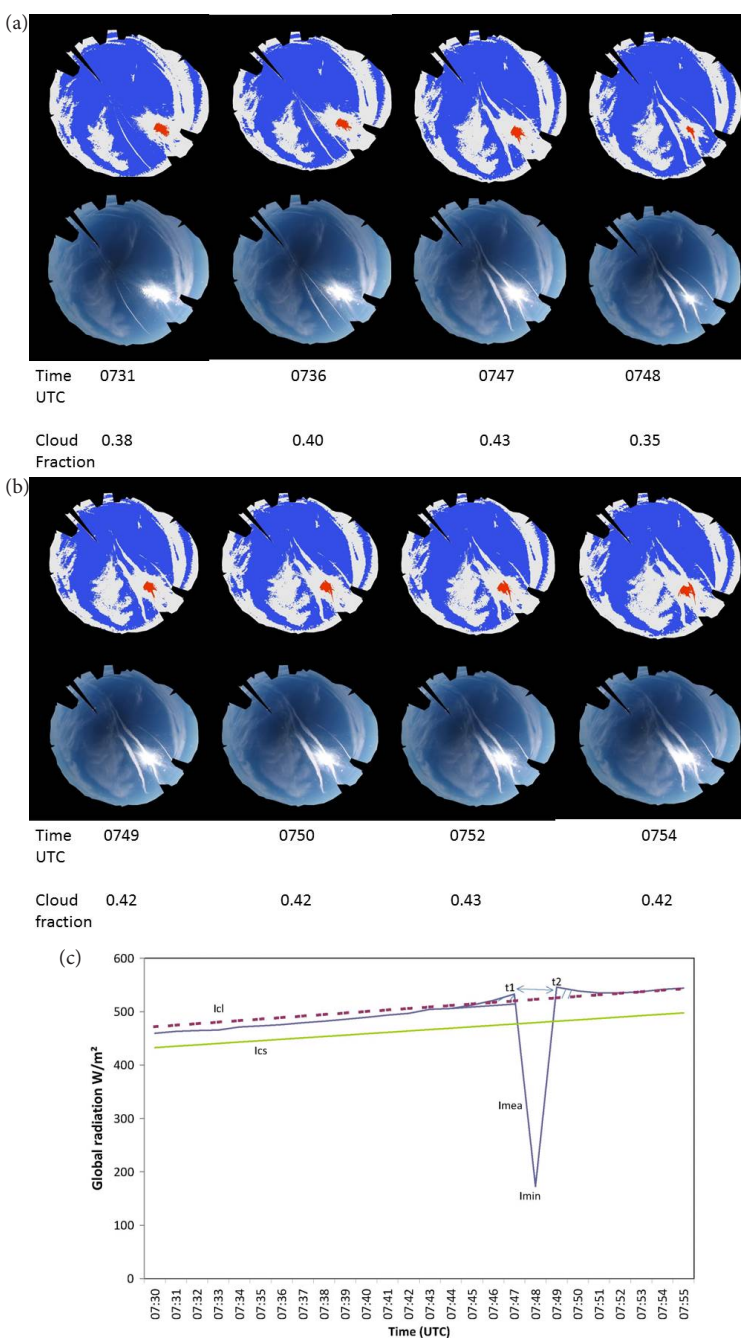

Figure 1. (a-c) Sequence of fish-eye photographs before and after a sun obstruction event by a contrail. The upper panel shows the photographs analysed by the software findcloud (CMS Schreder) which differentiates between cloud and clear sky pixels and determines the cloud fraction. (a) shows the photographs from 07:31, 07:36, 07:47 and 07:48 UTC (when the contrail moves between sun and observer), (b) shows photographs after the obstruction event. Below the photographs the time of the photograph and cloud fraction determined by the software findcloud is shown. The difference and the variations of the cloud fraction determined before and after the obstruction event (cloud fraction between 0.38 and 0.43 ) compared to the cloud fraction determined during the obstruction event (0.35) shows an uncertainty introduced by the dome of the fish-eye camera. (c) shows the global radiation which corresponds to the time of the photographs. Global radiation (blue line), cloudless reference $I_{\mathrm{cs}}$ (green line), interpolated global radiation $I_{\mathrm{cl}}$ (red dotted line) during an obstruction event by a contrail. (07:30 to 07:55 UTC, 23 September 2010). Due to surrounding (reflecting) clouds causing an increase in diffuse radiation the global radiation is higher as compared to cloudless conditions. The arrows show the duration of an obstruction event which has an uncertainty of 1 min (related to the measurement interval of $1 \mathrm{~min}$ ).

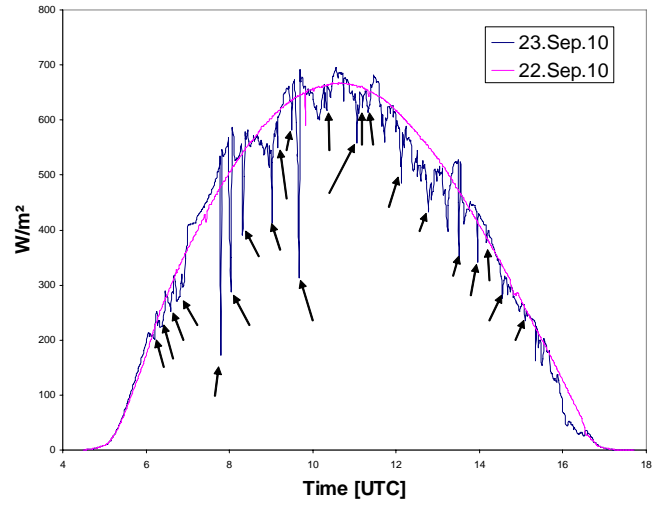

Figure 2. Global irradiance of two consecutive days: 22 and 23 September 2010. 22 September was a clear sky day without contrail persistence whereas on 23 September 2010 a strong contrail persistence (altogether 49 persistent contrails from 06:00 to 16:00 UTC) was observed. The arrows show the decrease in global irradiance due to contrails shading the sun (altogether 22 such events were observed). The clear sky day corresponds to the clear sky reference $I_{\mathrm{cs}}$. For simplicity purposes the model simulation which, perfectly agrees with the measurements is not shown (reproduced with permission from Weihs et al., 2013; Copyright (2013), AIP Publishing LLC.).

less conditions (with same solar zenith angle, aerosol optical thickness, water vapour and ozone concentration).

\subsection{Data analysis}

The parameters which were determined during the analysis were the maximum $R_{\max }$ and the mean reduction, $R_{\text {mean }}$, in global radiation during an obstruction event as well as the duration of the obstruction event. Assuming that the influence of surrounding clouds on diffuse and direct irradiance remains constant before, during, and after an obstruction event, it can be stated that the observed reduction in the global irradiance originates only from a reduction in the direct component.

Within the scope of the present investigation this reduction $R_{\max }$ of the direct and global irradiance was determined during a sun obstruction event by a contrail as

$R_{\max }=\frac{2 \cdot I_{\min }}{I_{\mathrm{cl} 1}+I_{\mathrm{cl} 2}}$,

where $I_{\mathrm{cl} 1}$ is the modelled global irradiance before the sun obstruction which corresponds to time $t_{1}, I_{\mathrm{c} 2}$ is the modelled global irradiance after the sun obstruction which corresponds to time $t_{2}, I_{\min }$ is the measured minimum global irradiance during the sun obstruction by the contrail. The method is illustrated in Fig. 1c.

In order to verify that the influence of the surrounding clouds remains the same before and after the obstruction event the modelled global radiation $I_{\mathrm{cl}}$ was used. For this reason the influence of the changing sun position is taken 
into account (Fig. 1c). The probability that, for example, subvisual clouds are disturbing the measurements obscuring the sun just at the same time and with the same duration as the contrails is low. This interpolation technique based on the calculation of $I_{\mathrm{cl}}$ is therefore a good means to determine the uncertainty of $R_{\max }$.

The duration of an obstruction was determined using the fish-eye photographs and, additionally, by looking at the length of a reduction in global irradiance as compared to the expected modelled global irradiance $I_{\mathrm{cl}}$ during the obstruction event (Fig. 1b, c).

The average reduction of the irradiance during an obstruction event $R_{\text {mean }}$ is calculated according to Eq. (2):

$R_{\text {mean }}=\frac{2 \cdot I_{\text {mean }}}{I_{\mathrm{cl} 1+I_{\mathrm{cl} 2}}} \quad$ with $\quad I_{\text {mea }}=\frac{1}{t_{2}-t_{1}} \int_{t_{1}}^{t_{2}} I_{\text {mean }}(t) \mathrm{d} t$.

$I_{\text {mea }}$ is the measured global radiation. The second quantity determined was the change in the daily irradiance sum $\left(E_{\text {mea }}-E_{\mathrm{cs}}\right)$ as compared to a cloudless global radiation day without any contrails $E_{\mathrm{cs}}$ (Fig. 2). In order to calculate the enhancement and reductions of global radiation by contrails and clouds - for the same time and day - first a reference clear sky global irradiance $\left(I_{\mathrm{cs}}\right)$ was calculated. This value was adjusted using a multiplication factor in order to obtain the cloudy global irradiance $I_{\mathrm{cl}}$. For a detailed description see Sect. 2.4.

The daily irradiance sum is the integral of the global radiation over the whole day

$E_{\text {mea }}=\int_{\text {sunrise }}^{\text {sunset }} I_{\text {mea }}(t) \mathrm{d} t$.

In order to calculate the daily irradiance sum to be expected without shading by contrails and cirrus clouds, the times of the day with cloudiness only composed of cirrus clouds and contrails were identified. To remove the direct effect (shading) of cirrus and contrails on the daily radiation sum in Eq. (3) the measured global irradiance $I_{\text {mea }}$ was replaced by the modelled clear sky irradiance $I_{\mathrm{cs}}$ for the periods of the day with cirrus clouds and contrails. A new daily irradiance sum $E_{\mathrm{cl}}$ was then obtained. The direct influence (shading and enhancement) of cirrus and contrails could then be determined by

$\Delta E_{\mathrm{cl}}=E_{\mathrm{cl}}-E_{\mathrm{mea}}$.

To take the influence of only contrails into account $I_{\text {mea }}$ was replaced during the time period with obstruction events by contrails or short time enhancements (see Fig. 1c) with $I_{\mathrm{cl}}$ and a daily irradiance sum $E_{\text {con }}$ was obtained. The influence of contrails at larger distances from the sun were not taken into account since contrails themselves develop into cirrus and their influence on the diffuse irradiance may not be differentiated any more.
The influence of contrails $\Delta E_{\text {con }}$ may be determined:

$\Delta E_{\mathrm{con}}=E_{\mathrm{con}}-E_{\mathrm{mea}}$.

\subsection{Radiative transfer (RT) modelling}

For the calculation of $I_{\mathrm{cs}}$ and $I_{\mathrm{cl}}$ the radiative transfer (RT) model interface uvspec from the LIBRADTRAN (Mayer and Kylling, 2005) package was used. Calculations were performed using SDISORT with two streams and the SBDART molecular absorption approach.

To use the RT model simulations as an interpolation tool to obtain $I_{\mathrm{cl}}$ the simulated global radiation was adjusted to the measured global radiation $I_{\text {mea }}$ before and after the obstruction event. In order to take the enhancement of global radiation due to cloudiness into account, a multiplication factor in the order of a maximum of 1.10 was used (Fig. 1c).

For the determination of $I_{\mathrm{cs}}$, which represents a cloudless day without any contrails, the RT model calculations were first compared with the measured global radiation of cloudless time periods ( 0 tenth cloud fraction) of the same day or of the next partly cloudless day, taking aerosol optical depth and solar position into account. In order to compensate for small discrepancies between RT model calculations and measurements of global radiation due to uncertainties in model input parameter determinations (e.g. optical depth, water vapour amount) or expected systematic measurement errors of $\pm 2 \%$, the model results were fitted to the measured global radiation by introducing a correction factor in the order of magnitude between 0.98 and 1.02 .

Uncertainties in the determination of $R_{\max }$ (see Eq. 1) may arise from fluctuations of the direct beam during the obstruction event or from fluctuations of the diffuse irradiance before, during and after the obstruction event. Since only cases without other clouds were selected - except for the contrails - close to or in front of the sun, only sub-visual clouds could therefore obstruct the direct beam at the same time as the contrails and lead to uncertainties in the determination of the global irradiance changes caused by contrails. As already mentioned above, the difference between the modelled global irradiance $I_{\mathrm{cl}}$ with the measured global irradiance $I_{\text {mea }}$ before and after the obstruction event is a good indicator of interferences by other clouds during the obstruction event.

However, the change in global irradiance was simulated for the implausible scenario that sub-visual clouds would obscure the sun just over the same time period as the contrails. The maximum optical depth of the sub-visual clouds amounts, according to Cadet et al. (2003), to 0.03. A maximum optical depth of the sub-visual clouds of 0.03 was therefore assumed and the uncertainty caused by sub-visual clouds by using the RT model interface uvspec was simulated. Maximum changes of the direct beam irradiance of $2 \%$ and of global irradiance of up to $1.7 \%$ were obtained representing at the same time one uncertainty of the determination of the effect of contrails. 
The second uncertainty mentioned above pertains to a changing diffuse irradiance before, during, and after the obstruction event (not related to irradiance reflected by contrails close to the sun). This may occur when larger opaque clouds would move close to the sun (these cases have been already removed) or for larger or changing cloud fractions before and after the obstruction event. We obtained a maximum difference between modelled $I_{\mathrm{cl}}$ and measured $I_{\text {mea }}$ irradiance before and after the obstruction event of $5 \%$. This is a good indicator for the changes in diffuse irradiance before, during and after an obstruction event.

The uncertainty of the determination of the daily radiation sum and of the influence of cirrus cloudiness and contrails on the daily radiation sum depends on the accuracy of $I_{\mathrm{cs}}$ and $I_{\mathrm{cl}}$ respectively. $I_{\mathrm{cs}}$ was adjusted to the measurements during cloudless time periods of the same day or of the nearest cloudless day. Possible systematic uncertainty of the radiation sensors is included in $I_{\text {mea }}$ and represent at the same time the uncertainty of $I_{\mathrm{cs}}$. Other uncertainties of $I_{\mathrm{cs}}$ arising from uncertainties in the input parameters are very low and below $0.5 \%$. Aerosol optical depth is being measured by AERONET so that the uncertainty of this input parameter is in the order of magnitude of the measurement uncertainty of AERONET. Water vapour is also provided by AERONET. Column ozone input data is taken from Brewer measurements performed at Sonnblick Observatory $\left(47^{\circ} 3^{\prime} \mathrm{N}, 13^{\circ} 0^{\prime} \mathrm{E}, 3106 \mathrm{~m}\right.$ altitude, $79 \mathrm{~km}$ horizontal distance). Assuming an uncertainty in column ozone of 100 Dobson units (DU) an uncertainty in global radiation of approximately $0.5 \%$ is obtained. An uncertainty of $100 \mathrm{DU}$ is however at least ten times higher than the spatial variability in column ozone within $100 \mathrm{~km}$ distance stated by Schmalwieser et al. (2008). The determination of the influence of contrails on the daily irradiance sum is calculated according to Eq. (5) making use of $I_{\mathrm{cl}}$. The accuracy of the daily irradiance sum depends on the accuracy of $I_{\mathrm{cl}}$ which is estimated at around $5 \%$.

\section{Case study}

We describe here a detailed case study on 22-23 September that serves as an example for the later statistical analysis. The first day was almost cloudless without any contrail persistence during the whole day. The diurnal range of global irradiance on this day shows a perfect bell shaped curve (Fig. 2). 23 September was a day with strong contrail persistence. Figure 2 shows [with arrows] all identified sun obstruction events by contrails. Altogether 49 contrails were observed, 22 of which moved between sun and observer. Reductions in global irradiance of up to $370 \mathrm{~W} \mathrm{~m}^{-2}(68 \%$, which means $R_{\max }=0.32$ ) were observed. Between the sun obstruction events, an increase in global irradiance is visible, compared to the day before. These radiation enhancements could not be explained by a reduction in aerosol optical depths between 22

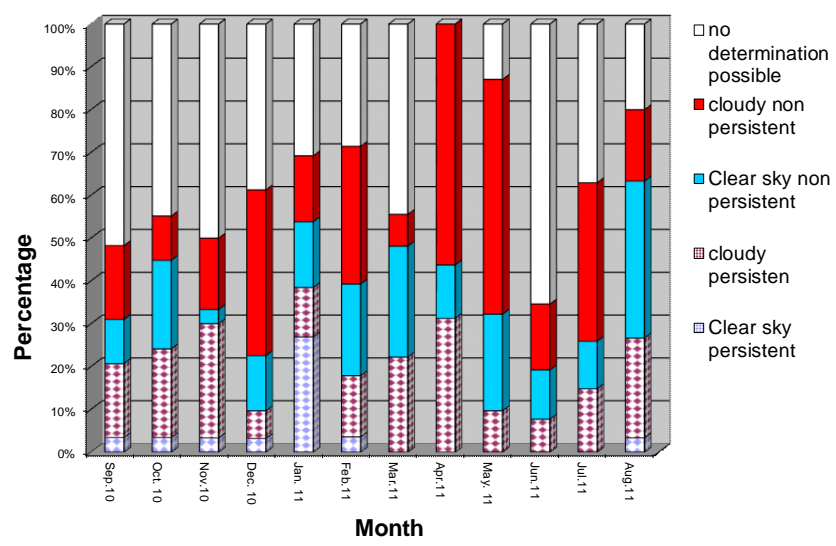

Figure 3. For each month the percentage of days with and without contrail persistence are shown. Many days (upper part of the columns referred to as "no determination possible") mostly with full cloud cover do not allow a determination as to the persistence of contrails. The red and blue parts of the columns are cloudy ("cloudy non persistent") and clear sky ("clear sky non persistent") days without contrail persistence, whereas the two lowest partitions of the columns show days with contrail persistence under cloudy ("cloudy persistent") and clear sky ("clear sky persistent") conditions.

and 23 September. On both days similar values were measured by AERONET. The radiation enhancements of up to $10 \%$ were caused by cirrus clouds and contrails. Additionally, just before and after the obstruction events, the contrails moving close to the sun led to an additional enhancement of up to $3 \%$. The maximum mean enhancement over a period of $30 \mathrm{~min}$ was around $8 \%$. During the course of the day an increase in cirrus cloudiness could be observed which represents a characteristic feature for many days with contrail persistence. The increase in cirrus cloud fraction and optical thickness of the cirrus clouds during the day led to a reduction in global irradiance during some periods of the afternoon.

\section{Statistics}

The number of days with contrail persistence during the period from September 2010 to August 2011 was determined (Fig. 3). A maximum persistence was reached in January 2011 with approximately $35 \%$ of all days showing contrail persistence. Overall contrail persistence is larger during late autumn, winter and early spring.

Besides persistence, $R_{\max }$ and $R_{\text {mean }}$ were computed for all sun obstruction events caused by contrails and where any interference by cirrus clouds during the events could be omitted (see Sect. 2). The results for $R_{\max }$ and $R_{\text {mean }}$ are shown in Fig. 4a and b respectively. The maximum $R_{\max }$ is $72 \%$. This corresponds to a reduction in global irradiance of $390 \mathrm{~W} \mathrm{~m}^{-2}$. The average of all $R_{\max }$ values is equal to $16 \%$. The average of all $R_{\text {mean }}$ values is equal to $8 \%$. The 
a)

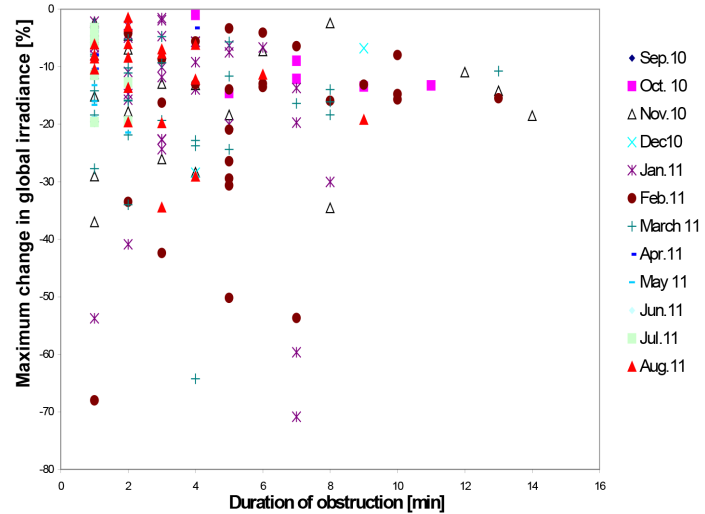

b)

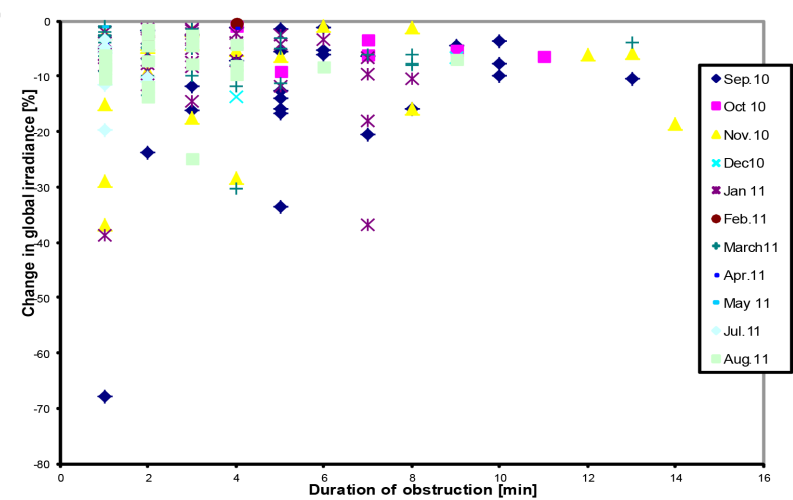

Figure 4. The maximum (a) and mean (b) reduction in global irradiance (during the shading event) as a function of the duration of the shading event by the contrails is shown for the 12 months that were analysed. For June 2011 no shading event was suited for the analysis because of interfering cloudiness which falsified the global irradiance decrease.

maximum duration of a sun obstruction event by a contrail is $15 \mathrm{~min}$ whereas the mean duration of a contrail remaining between sun and observer is $5 \mathrm{~min}$.

The median of the global radiation reductions as well as minimum, maximum and 25 and $75 \%$ quartiles are shown in Fig. 5. The largest reductions in global radiation occur for durations of sun obstructions by contrails of 7 to $8 \mathrm{~min}$. For longer durations the reductions become smaller. This is probably due to a broadening of the contrails with time, connected with a reduction of their optical thickness.

Other results that were obtained (not shown in figures) show that on average after or before obstruction events the short time enhancement of global radiation by contrails reached values up to $3 \%$ and on average over $30 \mathrm{~min}$ by up to $1.5 \%$. Mixture of contrails and cirrus may however lead to an enhancement in global irradiance of up to $8 \%$ over $30 \mathrm{~min}$. For a whole day, taking only the enhancements/reductions by contrails and cirrus between the sun obstruction events into account, changes in daily radiation sums between -2 and $+1.5 \%$ were obtained. Considering sun obstructions by con-

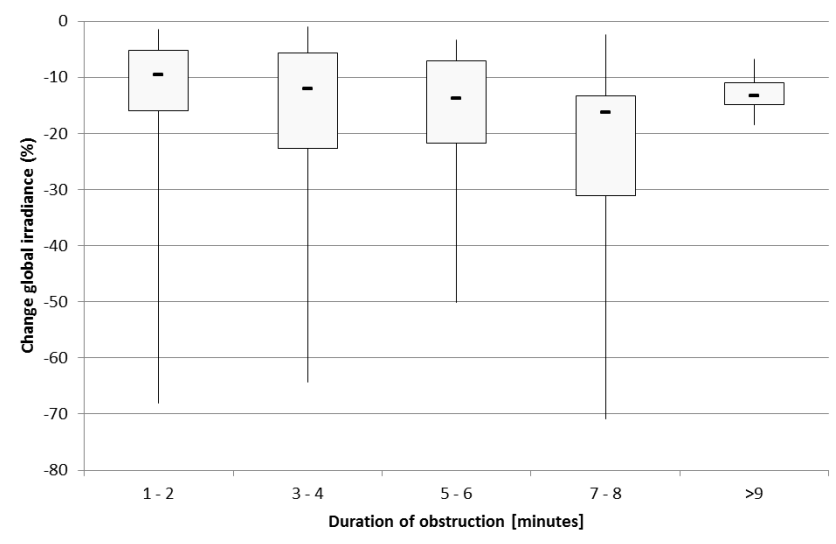

Figure 5. Box and whisker plots of the change in global irradiance as a function of the duration of the sun obstruction by contrails. The high-low lines show minimum and maximum values. The box shows the 25 and 75 quartile and the dash shows the median. Because of a low number of cases at larger durations of obstruction the change in global irradiance is shown as a function of 2 min intervals instead of $1 \mathrm{~min}$ intervals.

trails (under perfect cloudless conditions (no cirrus clouds)) reductions in daily radiation sums of up to $4.5 \%$ were obtained. Cirrus cloudiness therefore on average lowers the average diminutions in daily radiation sums. Since the origin of the cirrus cloudiness is not clearly identifiable (man-made, developing from contrails or of natural origin) and may either lead to an enhancement or to a reduction of the daily radiation sum, the focus will be solely put on the effects of contrails in the following section.

\section{Impact of contrails on photovoltaic energy gain}

The first impression, namely that short-term irradiance obstructions may have no impact on a daily scale is misleading. On the contrary, the pure reduction of irradiance (direct and diffuse) is of a magnitude and frequency that the energy loss of photovoltaic systems should be considered. For this purpose, over the whole investigation period, three different PV module types (crystalline silicon - c-Si: 220 Watt Peak (Wp) and $1.66 \mathrm{~m}^{2}$, amorphous silicon - a-Si: $95 \mathrm{Wp}$ and $1.45 \mathrm{~m}^{2}$ and cadmium telluride - CdTe: $75 \mathrm{Wp}$ and $0.72 \mathrm{~m}^{2}$ ) were studied by recording their current conversion efficiency at short circuit and their module temperature. From the current values the linearly temperature-corrected power values (IEC 60891, 2009) were calculated which were added up to the daily energy yield values $\left(Y_{\mathrm{d}}\right)$ following the method described in Sect. 2. From 28 days of persistent contrails a medium reduction in daily energy yield calculated on a basis of 23 days of about $0.35 \%$ (a-Si), $0.37 \%$ (CdTe) up to $0.44 \%$ (c-Si) was found. At the same time the irradiance enhancement resulting only from contrails was on average between $0.086 \%$ (a-Si) up to $0.119 \%$ (c-Si). The maximum 
Table 1. Energy yield losses for the given PV-technologies. The mean values in $\%$ are statistical values, the mean values in Wh were calculated from the fit in Fig. 6.

\begin{tabular}{cccc}
\hline & \multicolumn{3}{c}{ PV-technology } \\
\cline { 2 - 4 } & Crystalline Si & Amorphous Si & CdTe \\
\hline Mean loss of daily energy yield \\
\hline Single module $\left[\% \mathrm{~d}^{-1}\right]$ & 0.38 & 0.39 & 0.42 \\
Single module $\left[\mathrm{Wh} \mathrm{d}^{-1}\right]$ & 4.6 & 1.7 & 1.4 \\
System $1 \mathrm{~kW}_{\mathrm{p}}\left[\mathrm{Wh} \mathrm{d}^{-1}\right]$ & 20.9 & 17.5 & 18.8 \\
\hline \multicolumn{4}{c}{ Maximum loss of daily energy yield } \\
\hline Single module $\left[\% \mathrm{~d}^{-1}\right]$ & 3.33 & 2.12 \\
\hline \multicolumn{4}{c}{ Maximum increase of daily energy yield $^{2}$} \\
\hline Single module $\left[\% \mathrm{~d}^{-1}\right]$ & 1.63 & 0.94 \\
\hline
\end{tabular}

reductions were found in autumn and winter: $2.24 \%(\mathrm{c}-\mathrm{Si}$; 23 November 2011 with 22 persistent contrails) and $3.33 \%$ (c-Si; 9 January 2011 with 7 persistent contrails). The maximum increase in energy yield due to contrails was $1.63 \%$ (c-Si; 9 January 2011 with 7 persistent contrails).

The measurements were converted to daily energy yield in watt hours (Wh) per module and also normalized to an ideal photovoltaic model system with a size of $1000 \mathrm{Wp}$. On average, the loss for $\mathrm{c}-\mathrm{Si}$ is $4.6 \mathrm{Wh}$ (from daily $1197 \mathrm{Wh}$ ), for a-Si $1.7 \mathrm{Wh}$ (from daily $436 \mathrm{Wh}$ ) and for CdTe $1.4 \mathrm{Wh}$ (from daily $336 \mathrm{Wh}$ ) for the single modules, see Fig. 6. This corresponds to average values of $21 \mathrm{Wh}$ for c-Si (from daily $5444 \mathrm{Wh}$ ), $18 \mathrm{Wh}$ for a-Si (from daily $4592 \mathrm{Wh}$ ) and $19 \mathrm{Wh}$ for CdTe (from daily $4886 \mathrm{Wh}$ ) for an installed nominal capacity of $1 \mathrm{~kW}_{\mathrm{p}}$. All technologies show the maximum loss in energy yield for a duration of the obstruction of approximately $6 \mathrm{~min}$. The results are summarized in Table 1.

The losses seem small compared to the daily energy yields which are gained. Nevertheless, the maximum losses for c$\mathrm{Si}$ were 11,17 and $36 \mathrm{Wh} \mathrm{day}^{-1}$, respectively. For a small island system including one module and $2 \times 60 \mathrm{Ah}$ solar batteries the loss then would be up to $3 \mathrm{Ah}$ at a level of $12 \mathrm{~V} \mathrm{DC}$. This is up to $2.5 \%$ of the assumed storage capacity.

In total 22 of the 28 days of persistent contrails were found between August and the end of January which is a critical time for solar supply via island systems. Moreover, 3 days were found to show irradiances below $800 \mathrm{Wh} \mathrm{m}^{-2}$ for all 28 days. First, this demonstrates that persistent contrails have an impact mainly on days of high irradiances and therefore affect days of most value for solar energy gain. Second, it shows that the reduction in energy yield for solar applications may be relevant on days in autumn and winter as well as for systems with bad system balance or after a series of days of low irradiances (Abawi, 2013).

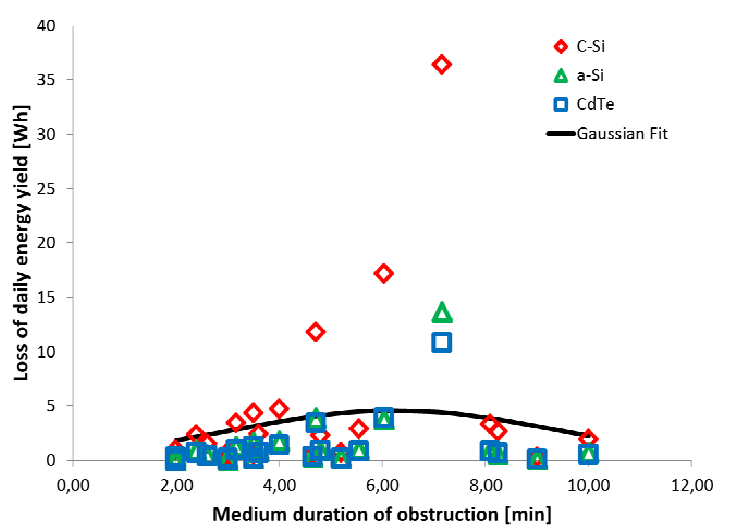

Figure 6. Loss of daily energy yield for the three modules types c$\mathrm{Si}(\diamond)$, a-Si $(\triangle)$ and $\mathrm{CdTe}(\square)$ as a function of the median duration of all the obstructions on a day with persistent contrails with on average 4.4 obstructions of the sun by contrails. The medium loss was estimated via a Gaussian fit, see solid line for the fit of the c-Si data.

\section{Conclusions}

Assuming thin cirrus cloudiness from anthropogenic origin and assuming a mean enhancement of $8 \%$ of the global irradiance (which was the mean enhancement over a period of 30 min between the obstruction events by contrails on some of the days), the following statement can be made: under all conditions met during days with persistent contrails, the sun must be obstructed between 35 and 40 min per hour for a considerable reduction in global irradiance to occur. This corresponds to approximately 7 to 8 contrails moving between the sun and observer. With thickening of the cirrus cloudiness (that may be of anthropogenic origin) we do not observe any enhancement of the radiation anymore but instead see a reduction. Altogether the decrease in global irradiance during a sun obstruction by a contrail is very high compared to the radiation enhancement. With a further increase in air traffic a threshold may be reached which automatically leads to reductions of daily solar energy yield on days with contrail persistence. For periods of successive days of bad weather, island system layouts may therefore, already under present conditions, come to a state that critically affects their performance. Losses in the daily energy yield for critical days then have to be considered.

Acknowledgements. This work was performed within the scope of KLIEN, Neue Energien 2020 project no. 822053 entitled "Einfluss von Sonnenspektrum und Klima auf die Performance von photovoltaischen Anlagen: Regionale Abschätzung des Sonnenenergiepotentials Österreichs". Data used in this paper can be obtained from the two first authors of this paper. We thank the reviewers for their valuable comments and their help in improving the present publication.

Edited by: S. Schmidt 


\section{References}

Abawi, J.: EUREC Master thesis; Analysis of Direct DC-Power Usage of Façade-Integrated Photovoltaics in a Test Façade; Loughborough University, 2013.

Cadet, B., Goldfarb, L., Faduilhe, D., Baldy, S., Giraud, V., Keckhut, P., and Réchou, A.: A sub-tropical cirrus clouds climatology from Reunion Island $\left(21^{\circ} \mathrm{S}, 55^{\circ} \mathrm{E}\right)$ lidar data set, Geophys. Res. Lett., 30, 1130, doi:10.1029/2002GL016342, 2003.

Feister, U. and Shields, J.: Cloud and radiance measurements with the VIS/NIR Daylight Whole Sky Imager at Lindenberg (Germany), Meteorol. Z., 14, 627-639, 2005.

Holben, B. N., Eck, T. F., Slutsker, I., Tanre, D., Buis, J. P., Setzer, A., Vermote, E., Reagan, J. A., Kaufman, Y., Nakajima, T., Lavenu, F., Jankowiak, I., and Smirnov, A.: AERONET - A federated instrument network and data archive for aerosol characterization, Remote Sens. Environ., 66, 1-16, 1998.

Holben, B. N., Tanre, D., Smirnov, A., Eck, T. F., Slutsker, I., Abuhassan, N., Newcomb, W. W., Schafer, J., Chatenet, B., Lavenue, F., Kaufman, Y. J., Vande Castle, J., Setzer, A., Markham, B., Clark, D., Frouin, R., Halthore, R., Karnieli, A., O’Neill, N. T., Pietras, C., Pinker, R. T., Voss, K., and Zibordi, G.: An emerging ground-based aerosol climatology: Aerosol Optical Depth from AERONET, J. Geophys. Res., 106, 12067-12097, 2001.

IEC 60891: Procedures for temperature and irradiance corrections to measured I-V characteristics of photovoltaic devices, 2nd Edn., 2009.
Mayer, B. and Kylling, A.: Technical note: The libRadtran software package for radiative transfer calculations - description and examples of use, Atmos. Chem. Phys., 5, 1855-1877, doi:10.5194/acp-5-1855-2005, 2005.

Minnis, P., Ayers, J. K., Palikonda, R., and Phan, D.: Contrails, Cirrus Trends, and Climate, J. Climate, 17, 1671-1685, 2004.

Pfister, G., MCKenzie, R. L., Lilley, J. B., Thomas, A., Forgan, B. W., and Long, C. N.: Cloud Coverage Based on All-Sky Imaging and Its Impact on Surface Solar Irradiance, J. Appl. Meteorol. 42, 1421-1434, 2003.

Schmalwieser, A. W., Erbertseder, T., Schauberger, G., and Weihs, P.: Sensitivity of UV erythemally effective irradiance and daily dose to spatial variability in total ozone, Photochem. Photobiol., 84, 1149-1163, 2008.

Stuber, N., Forster, P., Rädel, G., and Shine, K.: The importance of the diurnal and annual cycle of air traffic for contrail radiative forcing, Nature, 441, 864-867, 2006.

Weihs, P., Feitzinger, E., Baumgartner, D., Wagner, J., Rennhofer, M., Laube, W., and Gadermaier, J.: Investigation of the effect of contrails on direct and diffuse irradiance, AIP Conf. Proc. 1531, 536, 2013.

Wendler, G., Shulski, M., and Hartmann, B.: Potential climatic effects of cirrus contrails for the subarctic setting of Fairbanks, Alaska, Theor. Appl. Climatol., 81, 149-159, 2005. 